\section{(C) OPEN ACCESS}

\title{
An autopsy report of basilar artery aneurysm flow diversion complicated by postoperative day 3 hemorrhage from vessel rupture
}

\author{
Azeem A Rehman, ${ }^{1}$ Ryan C Turner, ${ }^{1}$ Stephanie Wright, ${ }^{2}$ SoHyun Boo, ${ }^{1}$ Ansaar T Rai ${ }^{1}$
}

'Department of Neurosurgery, West Virginia University Hospital, Morgantown, West Virginia, USA

${ }^{2}$ Department of Pathology, West Virginia University Hospital, Morgantown, West Virginia, USA

Correspondence to Dr Ansaar T Rai, ansaar.rai@gmail.com

Accepted 26 November 2018

\begin{abstract}
SUMMARY
A middle-aged patient presented with posterior circulation symptoms attributable to a large eccentric basilar trunk aneurysm. The planned treatment was flow diversion with loose coil packing which was successfully performed using a Pipeline Flex device deployed from the basilar to the left posterior cerebral artery. The complete procedure including live biplane fluoroscopy was digitally recorded. The patient had symptomatic improvement postoperatively and was discharged on day 1. The patient suffered a cardiac arrest on postoperative day 3 secondary to massive intraventricular and subarachnoid hemorrhage. An aneurysm rupture was suspected; however, postmortem examination showed an intact aneurysm sac. The hemorrhage was attributed to a small focal rent in the distal basilar artery next to an atheromatous plaque. The Pipeline device was visible through the rent. This is an autopsy report documenting an injury to the parent artery and not the aneurysm as a source of fatal delayed subarachnoid hemorrhage following flow diversion.
\end{abstract}

\section{BACKGROUND}

The etiology of delayed hemorrhage following flow diversion treatment of cerebral aneurysms is speculative. Possible mechanisms include changes in flow dynamics and aneurysm wall inflammation and/or thrombosis. ${ }^{12}$ Attempts to promote stability with coil augmentation have been reported ${ }^{3}$ but may not entirely prevent aneurysmal rupture. ${ }^{4}$ The previous literature has also focused on the aneurysm as the source of the hemorrhage. We present an autopsy case following flow diversion and light coiling where it was the artery and not the aneurysm that caused the fatal complication.

\section{CASE PRESENTATION}

A middle-aged patient presented with complaints of intermittent slurred speech, dizziness, difficulty ambulating, and generalized clumsiness. The patient had a smoking history of 30 pack-years and, of significance, had remotely undergone clipping of an unruptured anterior communicating artery aneurysm.

\section{INVESTIGATIONS}

Non-invasive imaging investigation demonstrated an eccentric basilar trunk aneurysm which was further evaluated with catheter angiography (figure 1). The basilar artery measured $4.8 \mathrm{~mm}$ at the level of the right anterior inferior cerebellar artery, $4.2 \mathrm{~mm}$ at the terminus proximal to the posterior cerebral arteries, and $2.8 \mathrm{~mm}$ at the left posterior cerebral artery in the mid-P1 segment. The aneurysm measured about $2 \mathrm{~cm}$ in mean dimensions.

\section{TREATMENT}

After extensive discussion with the patient including natural history, treatment options, and risks and benefits of each, a course of endovascular therapy using flow diversion and light coiling was planned. The rationale of this approach was vessel reconstruction with the flow diverter and gradual aneurysm thrombosis with the help of coils.

The patient was initiated on dual antiplatelet therapy in accordance with our institutional protocol. VerifyNow-P2Y12 was 167 PRU and VerifyNow-Aspirin was 407 ARU (Accriva Diagnostics, Newport Beach, California, USA), indicating effective platelet inhibition.

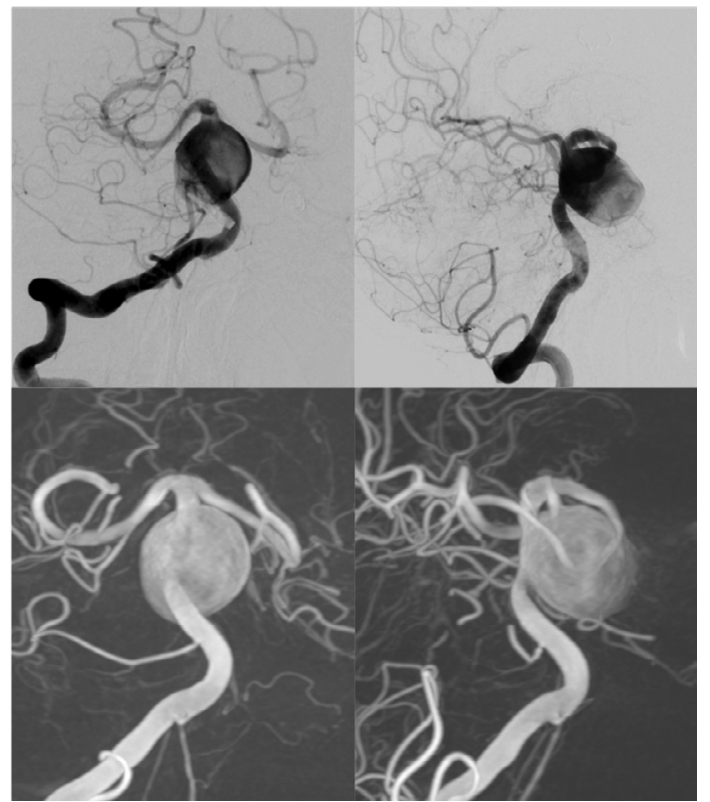

Figure 1 Anteroposterior and lateral views (top row) and $3 \mathrm{D}$ reconstructed multiplanar images (bottom row) from a right vertebral artery injection showing the large $2 \mathrm{~cm}$ eccentric aneurysm involving the middle third of the basilar artery trunk. 


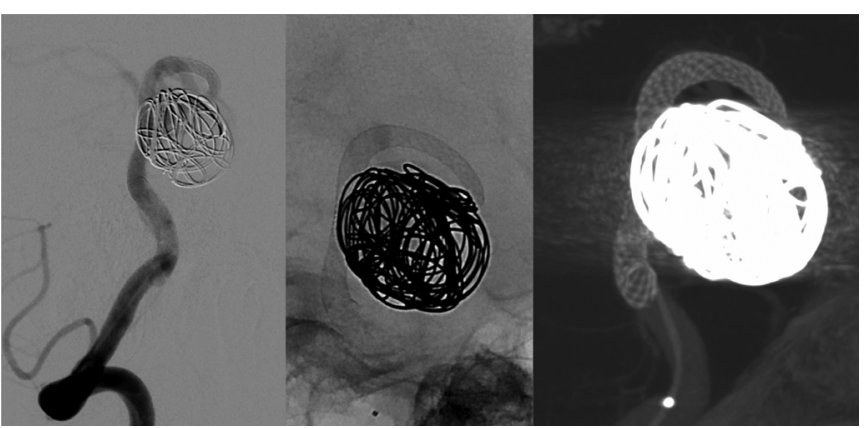

Figure 2 Oblique lateral working projections of postoperative control angiogram showing a well apposed and expanded Pipeline device, light coil packing, and mild stasis within the aneurysm sac.

The procedure was performed under general anesthesia. An 8 Fr sheath was placed in the right common femoral artery. An 8 Fr Infinity guide catheter (Stryker Neurovascular, Fremont, California, USA) was navigated over a 5 Fr diagnostic catheter into the cervical right vertebral artery. An SL-10 microcatheter (Stryker Neurovascular) was navigated over a Synchro microwire (Stryker Neurovascular) into the basilar artery aneurysm sac. Using parallel technique, a Phenom microcatheter (Medtronic, Minneapolis, Minnesota, USA) was navigated from the basilar artery into the right posterior cerebral artery (PCA). An initial attempt was made to deploy a $5 \times 30 \mathrm{~mm}$ Pipeline Flex stent (Medtronic) from the right PCA across the basilar aneurysm but the device could not be opened distally because of the tortuosity of the proximal PCA and likely size differential of the device relative to the distal artery. The Phenom microcatheter was repositioned into the left PCA which had a gentler curve to the basilar artery. A smaller $4.5 \times 30 \mathrm{~mm}$ Pipeline Flex stent was then successfully deployed from the left PCA into the basilar artery, landing proximally to the anterior inferior cerebellar artery jailing the coiling microcatheter in the aneurysm. Four Target XL (Stryker Neurovascular) coils $(18 \mathrm{~mm}$ x $50 \mathrm{~cm}$, $18 \mathrm{~mm} \times 50 \mathrm{~cm}, 16 \mathrm{~mm} \times 50 \mathrm{~cm}$, and $16 \mathrm{~mm} \times 50 \mathrm{~cm}$ ) were then deployed within the aneurysmal sac. A final angiogram showed mild stasis within the aneurysm (figure 2). Rotational angiography was also performed with low contrast imaging and 3D reconstruction demonstrating good wall apposition of the stent. The patient was extubated and transferred to the neurocritical care unit. Postoperative neurological examination did not show any acute deficits. Additionally, of note, the entire procedure including live fluoroscopy was digitally recorded for both planes and the accompanying video shows both the initial attempt to

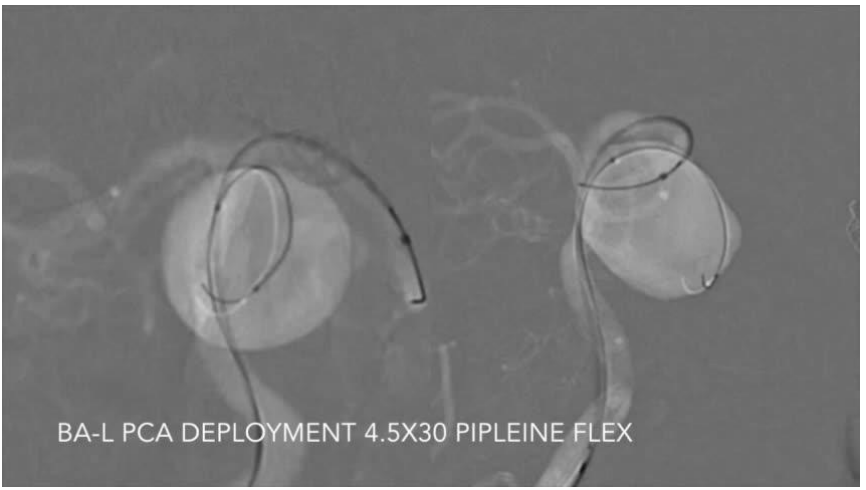

Video 1 The slightly accelerated video demonstrates almost the entire procedure with key steps labelled.

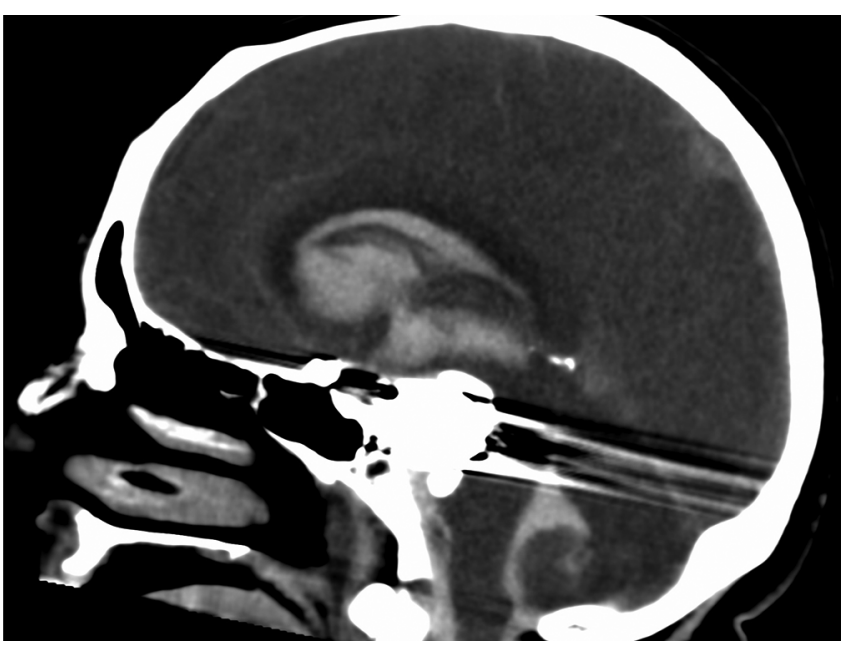

Figure 3 Sagittal image from a non-contrast CT scan of the brain showing massive subarachnoid hemorrhage with intraventricular extension.

deploy the first device and the final deployment of the second device (Video 1).

\section{OUTCOME AND FOLLOW-UP}

Postoperatively the patient recovered well without complications and demonstrated neurological improvement relating to the posterior circulation symptoms. The patient was discharged home on postoperative day 1 with the plan to continue dual antiplatelet therapy for 6 months. The patient was also provided with a steroid dose-pack for treatment of headaches believed to be related to aneurysm mass effect. Clinical follow-up was arranged for 2 weeks and cerebral angiogram arranged for 6 months.

On postoperative day 3 the patient had rapid onset loss of consciousness and cardiac arrest at home. Emergency medical services performed cardiopulmonary resuscitation in the field with return of spontaneous circulation. A CT scan on arrival showed massive subarachnoid and intraventricular hemorrhage (figure 3).

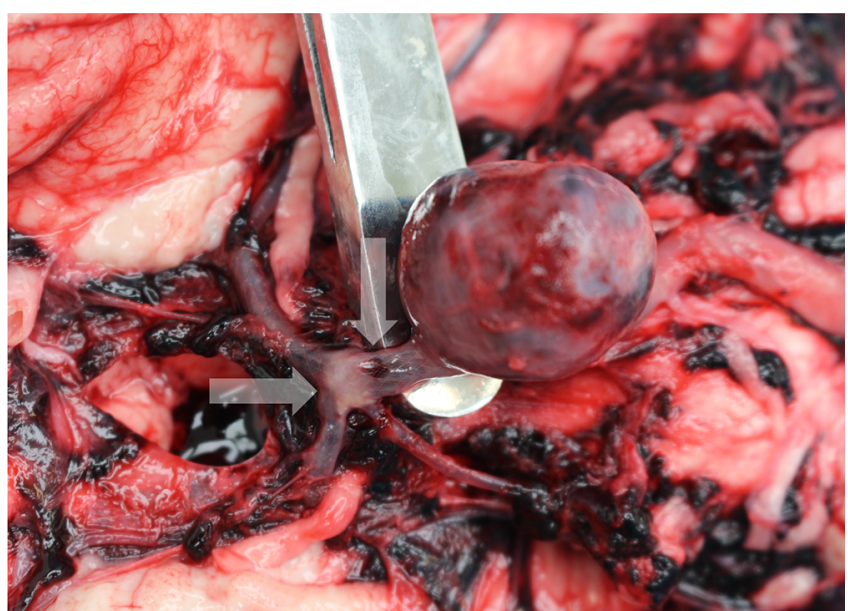

Figure 4 Gross postmortem examination shows diffuse subarachnoid hemorrhage and a completely intact aneurysm sac. A focal rupture point (vertical arrow) is identified at the level of the superior cerebellar arteries adjacent to an atheromatous plaque (horizontal arrow). The Pipeline device can be seen through the rupture point and the vessel wall traversing the basilar and left posterior cerebral arteries. 


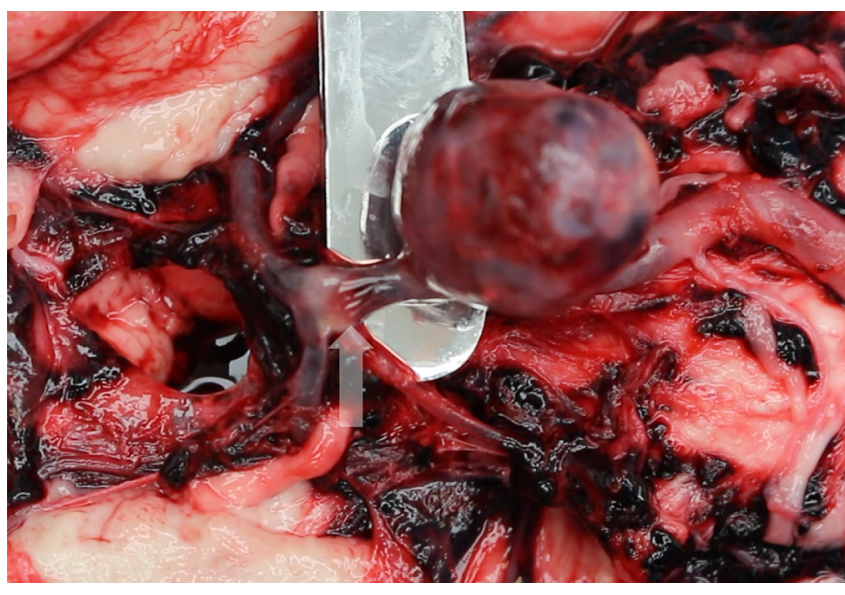

Figure 5 The right vertebral artery was injected with saline which is seen exiting out of the rupture point in the basilar artery (vertical arrow). No saline leak was observed from the aneurysm sac.

Neurological examination was consistent with brain death. The patient was taken off life support and died.

The patient's family consented to a postmortem examination. The autopsy was attended by one of the attending physicians and key portions of the autopsy were recorded and photographed.

The autopsy confirmed diffuse subarachnoid and intraventricular hemorrhage. The base of the brain was meticulously handled and examined to avoid iatrogenic injury to the operated region. The aneurysm was completely intact without evidence of rupture at any point. The source of the hemorrhage was localized to a small hole in the basilar artery distal to the aneurysm sac at the level of the superior cerebellar artery and just proximal to an atheromatous plaque at the basilar artery terminus (figure 4). The Pipeline device was visible through the rent and could also be traced from the basilar artery to the left PCA. Saline was injected in the right vertebral artery and was seen flowing out of the rupture point in the basilar artery (figure 5, Video 2), but no leak was observed from the aneurysm. Histological examination of the vessel wall did not reveal inflammatory changes or evidence of dissection (figure 6) other than the focal tear in the distal basilar artery.

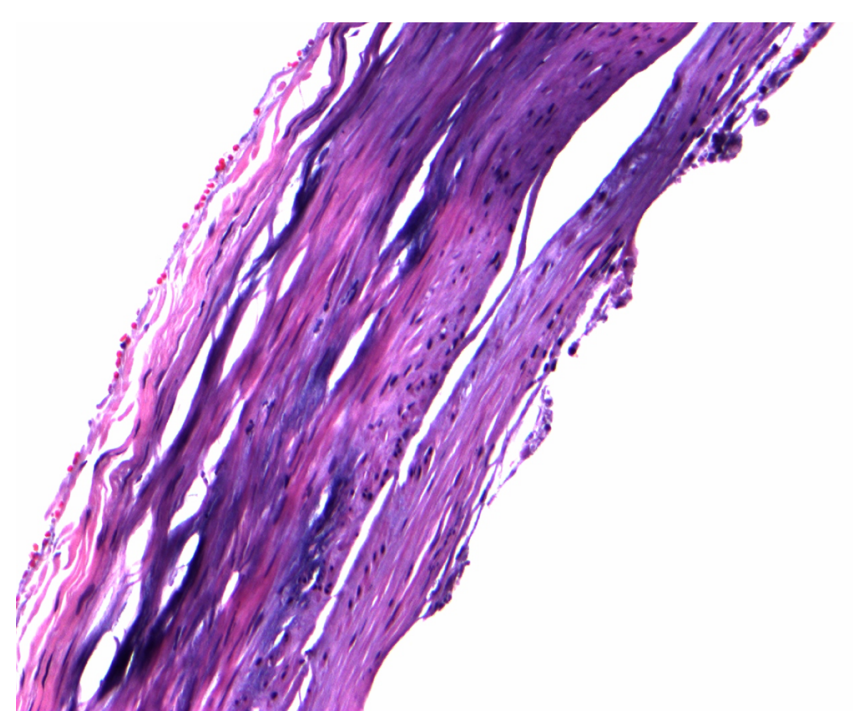

Figure 6 A section of the stented vessel wall (H\&E stain) adjacent to the tear did not show evidence of extended dissection or vessel wall inflammation.

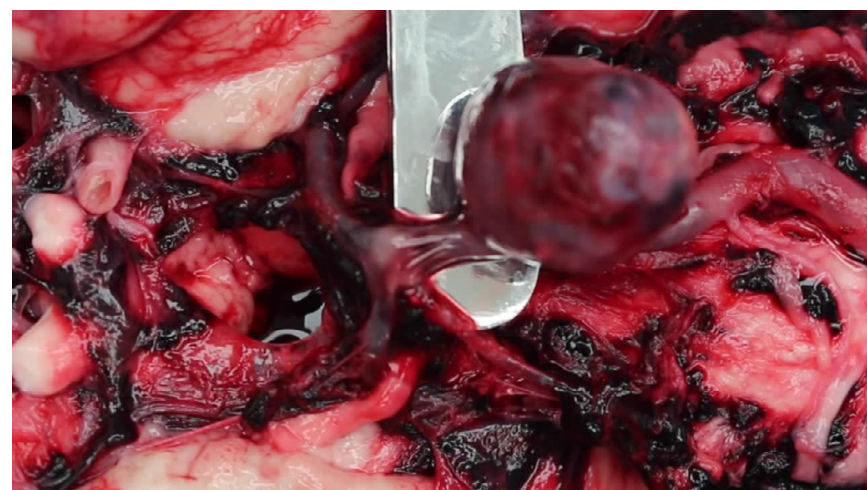

VIDEO 2 The right vertebral artery is injected with saline which is seen seeping out of the basilar artery rupture point. No saline leaked out of the aneurysm.

\section{DISCUSSION}

There has been one previous autopsy report of a case very similar to ours of a basilar trunk aneurysm treated with flow diversion and early fatal subarachnoid hemorrhage. ${ }^{6}$ However, the key difference is that in that case the aneurysm literally ripped apart whereas in our case the aneurysm sac was completely intact and the basilar artery developed a focal rupture in an area that was covered by the Pipeline device. We examined the entire procedure video to determine if there could be an iatrogenic etiology such as wire perforation or vessel dissection but could not find such a cause. The rupture also happened 3 days postoperatively which, if there was a wire perforation, would be expected to be more immediate.

The natural history of large or giant basilar trunk aneurysms is not benign ${ }^{7}$ and these continue to represent a surgical challenge requiring complex microsurgical ${ }^{8}$ or endovascular techniques incorporating flow diversion. ${ }^{9}$ For posterior circulation flow diversion, the reported rate of periprocedural stroke of $23 \%$ and mortality of $21 \%$ remains high. ${ }^{10}$

In our case, we do not know why the vessel developed a delayed focal rupture. The rupture is adjacent to an atheromatous plaque. We do not know if the radial force exerted by the device had any effect, but one speculation is of vessel 'stretching' and stress at the weak point where the device also tapers into the smaller left PCA. An unrecognized intraprocedural intimal vessel injury that subsequently dissected through the vessel wall is another possibility, although histological examination (other than the focal tear) did not reveal arterial dissection. Additionally, review of the recorded procedure did not show any suspicious events that could have led to arterial dissection. Deployment of a braided stent requires more manipulation than a laser-cut device with 'pull' and 'push' techniques to fully expand the device. This manipulation could also be traumatic to a weakened artery. High-fidelity preoperative vessel wall imaging in

\section{Learning points}

Early postoperative subarachnoid hemorrhage following flow diversion can arise from the parent artery and not just the aneurysm sac.

- Atheromatous segments may make the parent artery more prone to injury during device manipulation and deployment, especially for braided devices.

- Postmortem examination offers substantial insight into procedural complications. 
the future may provide a better assessment of the target vessel in terms of device selection. An alternative option for a case such as this could be stent-assisted coiling using a laser-cut nitinol stent and standard coils.

Contributors AAR: manuscript preparation. RCT: manuscript preparation. SW: data collection. SB: data collection. AR: manuscript preparation.

Funding The authors have not declared a specific grant for this research from any funding agency in the public, commercial or not-for-profit sectors.

Competing interests None declared.

Patient consent for publication Not required.

Provenance and peer review Not commissioned; externally peer reviewed.

Data sharing statement There are no additional data.

Open access This is an open access article distributed in accordance with the Creative Commons Attribution Non Commercial (CC BY-NC 4.0) license, which permits others to distribute, remix, adapt, build upon this work non-commercially, and license their derivative works on different terms, provided the original work is properly cited, appropriate credit is given, any changes made indicated, and the use is non-commercial. See: http://creativecommons.org/licenses/by-nc/4.0/.

\section{REFERENCES}

1 Hampton T, Walsh D, Tolias C, et al. Mural destabilization after aneurysm treatment with a flow-diverting device: a report of two cases. J Neurointerv Surg 2011;3:167-71.
2 Pierot L, Spelle L, Berge J, et al. Feasibility, complications, morbidity, and mortality results at 6 months for aneurysm treatment with the Flow ReDirection Endoluminal Device: report of SAFE study. J Neurointerv Surg 2018:10:765-70.

3 Nelson PK, Lylyk P, Szikora I, et al. The pipeline embolization device for the intracranial treatment of aneurysms trial. AJNR Am J Neuroradiol 2011;32:34-40.

4 Fischer S, Perez MA, Kurre W, et al. Pipeline embolization device for the treatment of intra- and extracranial fusiform and dissecting aneurysms: initial experience and longterm follow-up. Neurosurgery 2014;75:364-74.

5 Kan P, Siddiqui $A H$, Veznedaroglu E, et al. Early postmarket results after treatment of intracranial aneurysms with the pipeline embolization device: a U.S. multicenter experience. Neurosurgery 2012;71:1080-8.

6 Fox B, Humphries WE, Doss VT, et al. Rupture of giant vertebrobasilar aneurysm following flow diversion: mechanical stretch as a potential mechanism for early aneurysm rupture. BMJ Case Rep 2014;2014.

7 Lenga $P$, Hohaus $C$, Hong $B$, et al. Giant intracranial aneurysms of the posterior circulation and their relation to the brainstem: analysis of risk factors for neurological deficits. J Neurosurg 2018:1-7.

8 Goroshchenko SA, Petrov AE, Rozhchenko LV, et al. [Surgical treatment of large and giant vertebrobasilar aneurysms manifested by brainstem compression symptoms]. Zh Vopr Neirokhir Im N N Burdenko 2018;82:32-7.

9 Natarajan SK, Lin N, Sonig A, et al. The safety of Pipeline flow diversion in fusiform vertebrobasilar aneurysms: a consecutive case series with longer-term follow-up from a single US center. J Neurosurg 2016;125:111-9.

10 Kiyofuji S, Graffeo CS, Perry A, et al. Meta-analysis of treatment outcomes of posterior circulation non-saccular aneurysms by flow diverters. J Neurointerv Surg 2018;10:493-9.

Copyright 2018 BMJ Publishing Group. All rights reserved. For permission to reuse any of this content visit https://www.bmj.com/company/products-services/rights-and-licensing/permissions/

BMJ Case Report Fellows may re-use this article for personal use and teaching without any further permission.

Become a Fellow of BMJ Case Reports today and you can:

- Submit as many cases as you like

- Enjoy fast sympathetic peer review and rapid publication of accepted articles

- Access all the published articles

- Re-use any of the published material for personal use and teaching without further permission

For information on Institutional Fellowships contact consortiasales@bmjgroup.com

Visit casereports.bmj.com for more articles like this and to become a Fellow 